from urine specimens prepared by adding $4.5 \mathrm{ml}$ to $4.5 \mathrm{ml}$ of cobas ${ }^{\circledR}$ PCR media, and from swabs discharged in $1.0 \mathrm{ml}$ of the same media. The cobas ${ }^{\circledR} 4800$ system loaded extracted DNA, controls and amplification reagents into 96-well amplification plates. Plates were then covered and placed into the cobas ${ }^{\circledR}$ z480 real-time PCR instrument. Retesting in both cobas ${ }^{\circledR} 4800$ and TaqMan 48 assays was performed to further investigate specimens providing discrepant results.

Results A total of 708 clinical specimens (293 male urines and 415 swab specimens, of which 356 self-collected vaginal swabs, 45 swabs from cervix and 14 swabs from male urethra) were analysed. The results were concordant in $98.5 \%$ of cases $(697 / 708)$. Out of 708 samples, 50 provided positive results ( 17 men, 33 women). Three urine specimens and eight vaginal swabs provided discrepant results. Out of five specimens providing positive results in the reference CT assay, four were false-negative in the cobas ${ }^{\circledR} 4800$ CT test. Out of six positive results by the cobas ${ }^{\circledR} 4800$ assay, five were falsepositive. After discrepancy analysis, the prevalence of the CT infection was $7.7 \%(55 / 708)$. The sensitivity and specificity of the cobas ${ }^{\circledR} 4800$ CT/NG test were $92.7 \%$ (urine specimens $94.1 \%$, swab specimens $92.1 \%$ ) and $99.2 \%$, respectively. The three false-negative results in swabs could be explained by the procedure not consistent with the manufacturer's instructions. Indeed, swabs were not inserted directly into the cobas ${ }^{\circledR}$ media vials.

Conclusion The $\operatorname{cobas}{ }^{\circledR} 4800$ CT/NG test is suitable for high through-put identification of the $C$ trachomatis infection.

\section{P3-S1.15 THE MOLECULAR DIAGNOSIS OF RECTAL GC AND CT INFECTIONS USING THE FTA ELUTE CARD FOR SPECIMEN COLLECTION AND THE REAL-TIME MULTIPLEX PCR FOR DETECTION}

doi:10.1136/sextrans-2011-050108.415

K H Chi, C Y Chen, T Ye, E Nachamkin, R Ballard. CDC, Atlanta, USA

Background To evaluate the potential use of the Whatman Indicating FTA Elute Micro Card for collection, transport, and storage of rectal swab specimens for subsequent detection of STD pathogens in MSM using a TaqMan-based real-time multiplex PCR.

Methods Two rectal swabs were obtained by the physician from each participant in a study to determine carriage of STD pathogens among MSM. One of the swabs was placed into a tube containing $1 \mathrm{ml}$ of Genelock transport medium and while the other swab was firmly pressed onto an FTA Card with three side to side motions held at approximately $60^{\circ}$ angle each time. Genomic DNA was eluted from three discs ( $3 \mathrm{~mm}$ diameter) punched out of each card after storage at room temperature for up to 6 months and tested by a real-time multiplex PCR assay which simultaneously detects lymphogranuloma venereum (LGV), non- LGV, Chlamydia trachomatis (CT), and Neisseria gonorrhoeae (GC), and human DNA control. For comparison, an aliquot of sample from genelock tube was extracted using the Qiagen DNA mini kit and tested with same real-time multiplex PCR assay.

Results Using purified DNA obtained from the Genelock specimens, the real-time multiplex PCR assay detected nine GC and 17 nonLGV CT; while 7 GC and 15 non-LGV CT were detected in DNA samples eluted from the FTA Cards and used directly for PCR. There were three GC and non-LGV co-infections and no LGV was detected using both specimen collection methods. A substantial number of specimens were found to be PCR inhibitory either collected in Genelock (18.3\%) or on FTA Cards (15.4\%).

Conclusions The FTA Elute Micro Card allows stable storage and convenient transport of rectal swab specimens at room temperature. DNA can be eluted from the card with simple processes instead of numerous purification procedures for downstream real-time PCR amplification and aetiology detection. This preliminary evaluation shows the potential use of FTA Card for rectal specimen collection and PCR testing, and may also provide a cost-saving alternative to expensive international shipping of specimens on dry ice from remote study sites.

\section{P3-S1.16 COMPARISON OF THE ABBOTT M2000 REALTIME CT ASSAY FOR CHLAMYDIA TRACHOMATIS MONITORING IN TANZANIA COMPARED TO THE ROCHE AMPLICOR CT ASSAY}

doi:10.1136/sextrans-2011-050108.416

${ }^{1} \mathrm{P}$ Agreda, 'L Dize, 'S West, ${ }^{2} \mathrm{~J}$ A Williams, ${ }^{2} \mathrm{~B}$ Van Der Pol, ${ }^{1} \mathrm{C}$ A Gaydos. ${ }^{1} J o h n s$ Hopkins University, Baltimore, USA; ${ }^{2}$ Indiana University USA

Background The Abbott m2000 RealTime CT assay was evaluated as a new option for the detection of Chlamydia trachomatis in specimens obtained from Tanzania, and its performance was compared to the performance of the Roche Amplicor CT Assay.

Methods Duplicate swab specimens were collected from villages throughout Tanzania. 304 duplicate samples were shipped to the Johns Hopkins STD laboratory at $2-8^{\circ} \mathrm{C}$ for the detection of $C$ trachomatis. All swab specimens were shipped in a dry state, expressed in $1 \mathrm{ml}$ of sterile molecular grade DEPC water upon arrival, and analysed using the Roche Amplicor CT assay. Prior to Roche Amplicor amplification and detection, DNA extraction was performed using the Roche Magna Pure LC robot. The duplicate swab specimens were shipped to Indiana University for Abbott m2000 RealTime CT assay analysis. The bacterial load was measured by the DC value of the m2000 RealTime CT.

Results Of 304 specimens, $44(14.5 \%)$ were positive for CT via Roche Amplicor CT assay, and 53 (17.4\%) were positive for CT via Abbott m2000 RealTime CT assay. The relative quantitation for the m2000 assay ranged from DC 0.62 to DC 22.16. If the Roche PCR assay was considered to be the reference standard, the Abbott m2000 RealTime CT assay sensitivity was 44/44 (100\%), specificity was $251 / 260$ (96.53\%), positive predictive value was $251 / 251(100 \%)$, and negative predictive value was $44 / 53$ (83.01\%). The $\kappa$ score was 0.890. Discordant specimens, which were determined to be negative by Roche Amplicor and positive by Abbott m2000 RealTime, were tested by Gen-Probe TMA. Of nine discordant tests, two were positive, five were negative, and two were of insufficient volume for retesting. After discordant testing, there appeared to be five samples that were graded to be false positives by m2000. The Abbott m2000 RealTime CT assay sensitivity remained $100 \%$, while specificity increased to $256 / 258$ (99.2\%). The negative predictive value increased to $46 / 48$ (95.83\%). The $\kappa$ score was 0.9748 after discordant results were further analysed.

Conclusions Abbott m2000 RealTime CT assay demonstrates excellent sensitivity and specificity compared to the Roche Amplicor CT Assay for the detection of $C$ trachomatis. It may be advantageous to be able to measure the relative concentration for CT in some epidemiologic studies.

\section{P3-S1.17 SYNDROMIC MANAGEMENT OF CERVICITIS AND VAGINAL DISCHARGE AT A STI CLINIC IN JAMAICA: LOW CURE RATES FOR CHLAMYDIAL INFECTION AND TRICHOMONIASIS}

doi:10.1136/sextrans-2011-050108.417

${ }^{1} \mathrm{M}$ Hobbs, ${ }^{2} \mathrm{C}$ Anderson, ${ }^{2} \mathrm{~T}$ Hylton-Kong, ${ }^{2} \mathrm{~S}$ Eastman, ${ }^{1} \mathrm{~K}$ Rich, ${ }^{3} \mathrm{M}$ Gallo, ${ }^{3} \mathrm{~J}$ LegardyWilliams, ${ }^{4} \mathrm{E}$ Costenbader, ${ }^{4} \mathrm{M}$ Steiner, ${ }^{3} \mathrm{~L}$ Warner. ${ }^{1}$ University of North Carolina, Chapel Hill, USA; ${ }^{2}$ Comprehensive Health Centre, Center of Excellence, Kingston, Jamaica; ${ }^{3}$ Centers for Disease Control and Prevention, USA; ${ }^{4}$ Family Health International, Research Triangle Park, USA

Background Management of cervicitis and abnormal vaginal discharge in Jamaica is based on the syndromic approach recommended by the 